\title{
Transcriptional control of the murine polymeric IgA receptor promoter by glucocorticoids
}

\author{
TONY W. H. LI, ${ }^{1}$ JIAFANG WANG ${ }^{1}$ J ASON T. LAM, ${ }^{2}$ EDGAR M. GUTIERREZ, \\ R. SERGIO SOLORZANO-VARGUS, ${ }^{3}$ HUGH V. TSAI, ${ }^{1}$ AND MARTÍN G. MARTÍN ${ }^{1}$ \\ 'Department of Pediatrics, Division of Gastroenterology and Nutrition, and 2Department of \\ Physiology, University of California Los Angeles School of Medicine, Los Angeles 90095-1752; \\ and ${ }^{3}$ Department of Biology, California State University, Northridge, California 91330
}

\begin{abstract}
Li, Tony W. H., J iafang Wang, J ason T. Lam, Edgar M. Gutierrez, R. Sergio Solorzano-Vargus, Hugh V. Tsai, and Martín G. Martín. Transcriptional control of the murine polymeric IgA receptor promoter by glucocorticoids. Am. J. Physiol. 276 (Gastrointest. Liver Physiol. 39): G1425G1434, 1999.-Glucocorticoids have been implicated as an important regulator of intestinal epithelial cell ontogeny. The polymeric IgA receptor ( $\mathrm{plgR}$ ) is expressed in the intestinal epithelial layer and is regulated by several mediators, including glucocorticoids. The mechanism of how corticosteroids alter the transcriptional regulation of $\mathrm{plgR}$ expression has not been defined. In this study, we demonstrated that glucocorticoids upregulate steady-state plgR mRNA levels in the proximal intestine of suckling rats and in the IEC- 6 intestinal cell line. We performed functional analysis of the 5'-flanking region in the presence of glucocorticoids and its receptor using the intestinal cell line Caco-2. We screened $4.7 \mathrm{~kb}$ of the upstream region of the murine gene and identified the most potent steroid response element to reside between nt -215 and -163 relative to the start of transcription. Substitution mutation analysis of this region identified the location of the putative steroid response element to be between nt -195 and -176. In vitro DN ase I footprint analysis using the recombinant glucocorticoid receptor DNA binding domain confirmed a single area of protection that spans the nt identified by mutagenesis analysis. Electrophoretic mobility shift assays of the putative element confirmed the binding of both recombinant and cell synthesized glucocorticoid receptor in a specific manner. In summary, we report the identification and characterization of the glucocorticoid-DNA response element located in the immediate 5'-upstream region of the murine pl gR gene.
\end{abstract}

ontogeny; secretory component; immunoglobulin A; mucosa; intestine

THE POLYMERIC I gA receptor ( $\mathrm{plgR}$ ) is an integral membrane protein that is expressed by various secretory epithelial cells. The physiological role of the receptor is to bind and transport dimeric IgA antibodies across various epithelial layers, including the intestine. Once the receptor-immunogl obulin complex reaches the apical membrane of theintestinal epithelial cell, a cleaved portion of the receptor named secretory component, remains attached to the antibody and presumably protects it from degradation by digestive enzymes (21). Within the intestinal lumen, secretory IgA plays a

The costs of publication of this article were defrayed in part by the payment of page charges. The article must therefore be hereby marked "advertisement" in accordance with 18 U.S.C. Section 1734 solely to indicate this fact. critical role in reducing the adhesion of microbes to the epithelial layer (20).

Polymeric receptor expression is regulated by a variety of stimulants including hormones, cytokines, growth factors, and metabolic products (16). The receptor is also expressed in a developmentally specific manner, and in the proximal intestine of rats mRNA levels increase shortly after the time of weaning $(5,25)$. Such a developmental pattern of expression is not unique to plgR; in fact several other genes expressed by the epithelial cells of the intestine are either induced or repressed at the time of weaning (14). Thus the acquisition by the enterocyte of the adult phenotype and the induction or repression of these developmentally regulated proteins are temporally coordinated at the time of weaning in a uniform and well-documented manner (13).

A central question in the field of enterocyte adaptation is which factor(s) is responsible for coordinating the timely regulation of these various genes at weaning? Diamond (9) proposed a model in which both hardwired and environmental stimuli may be responsible for initiating the adaptive changes. In general, studies show that genes regulated in the intestine at the time of weaning are controlled by a poorly defined internal, hardwired clock and that changes in diet and/or environment play only a marginal role in altering its expression pattern (14).

The most thoroughly studied intrinsic modulators of the ontogenic process are glucocorticoid hormones (14). In rodents, the endogenous surge of corticosteroids occurs just before weaning, implicating this hormone as a good candidate master control hormone. Substantial evidencesuggests that exogenous corticosteroids administered during the suckling phase alter the level of transcription of several genes expressed in the intestine (13). Despite this in vivo evidence and the cloning of several of these genes, the exact mechanism of how steroids influencethetranscription of these devel opmentally regulated genes has not been defined (14).

We previously reported the complete genomic organization of the murine pl gR gene, including $4.7 \mathrm{~kb}$ of the 5 '-flanking region (24). More recently, we have identified the upstream 5 ' elements that control the basal expression of the gene's minimal promoter in transiently transfected Caco-2 cells $(24,25)$. Moreover, we determined that plgR mRNA steady-state levels increase dramatically at the time of weaning. To evaluate the potential role of glucocorticoids in inducing $\mathrm{plgR}$ expression, we studied both suckling animals and the intestinal cell line IEC-6. In the current investigation, 
we show that plgR steady-state mRNA levels are enhanced in devel oping intestine and IE C-6 cells treated with glucocorticoids. To define the mechanism of this regulation, we evaluated the entire cloned upstream region $(4.7 \mathrm{~kb})$ of the murine $\mathrm{pl} \mathrm{gR}$ gene using transient transfection assays of sequentially shorter and mutant clones. The glucocorticoid response el ement was identified and further characterized using in vitro DNase I footprint and electrophoretic mobility shift assays (EMSA).

\section{MATERIALS AND METHODS}

Cell culture and DNA transfections. The human intestinal Caco-2 cell line was cultured in high glucose (4.5 g/l) DME M (Mediatech) containing 20\% fetal bovine serum (FBS; Omega Scientific), $100 \mathrm{U} / \mathrm{ml}$ penicillin, and $100 \mu \mathrm{g} / \mathrm{ml}$ streptomycin. The rat intestinal IEC-6 cell line was maintained under similar conditions but used $10 \%$ calf serum instead. Both cell lines were obtained from American Type Culture Collection and grown in a humidified atmosphere containing $5 \% \mathrm{CO}_{2}$ at $37^{\circ} \mathrm{C}$

IEC-6 cells used for RNA isolation were grown to confluency in T75 flasks. The cells were washed and then treated with either $10^{-6} \mathrm{M}$ of dexamethasone in charcoal-stripped $20 \%$ FBS or steroid-free medium. The cells were then incubated for $24 \mathrm{~h}$ before RN A extraction.

Because IEC-6 cells have a low transfection efficiency via the calcium phosphate method, transient transfection studies were limited to Caco-2 cells. Plasmid DNA purified by the Qiafilter maxi prep kit (Qiagen) method was used for transfections. Cells were cotransfected with the glucocorticoid receptor (GR) expression vector ( $1 \mu \mathrm{g} /$ well, kindly provided by $\mathrm{K}$. Yamamoto, University of California, San Francisco) and the cytomegal ovirus $\beta$-galactosi dase vector $(0.5 \mu \mathrm{g} / \mathrm{well})$ to standardize for transfection efficiency. Freshly confluent Caco-2 cells were washed with PBS and seeded at $4 \times 10^{5}$ cells/35 $\mathrm{mm}$ after treating with trypsin EDTA. The cells were incubated at $37^{\circ} \mathrm{C}$ with $5 \% \mathrm{CO}_{2}$ for $18-20$ h before the transfection.

Subconfluent cells (40-60\%) were transfected using the calcium phosphate mammalian cell transfection kit (5 Prime $\longrightarrow 3$ Prime). The transfection was done according to the suggested protocol of the manufacturer with some minor modifications. Two sets of six-well plates were prepared for each plasmid tested. Twenty-four hours after the transfection, cells were washed with PBS; then one plate was treated with DMEM containing charcoal-treated $20 \%$ FBS, $10^{-6} \mathrm{M}$ dexamethasone and antibiotics (previously described), whereas the other plate was treated with charcoal-stripped steroid-free medium. Twenty-four hours later, the cells were rinsed, lysed, collected, and centrifuged, and extracts were stored at $-70^{\circ} \mathrm{C}$ until analyzed. All experiments were repeated in three to six-well plates at least twice.

Luciferase and $\beta$-galactosidase assays. The reporter gene assays were measured on the Monolight 2010 luminometer (Analytical Luminescence Laboratory). The luciferase assay was done by using the enhanced luciferase assay kit by Analytical Luminescence Laboratory. The $\beta$-galactosidase measurements were done using the Galacto-Light chemiluminescent reporter assay by Tropix. Both assays were done according to the protocol of the manufacturer.

RNA extraction and mRNA expression. RNA samples were taken from the duodenum of Sprague-Dawley rats and from IEC-6 cells. The animals used were prepared as described previously (26). Corticosterone acetate (Sigma) was administered subcutaneously (100 $\mu \mathrm{g} / \mathrm{g}$ body wt) on alternate days beginning on day 7 of life. Tissue was isolated from the proximal duodenum either 3 or 7 days later. RNA was extracted by using a modified protocol of Chomczynski's guanidine isothiocynate method. Tissue was homogenized using a Polytron and guanidinium thiocyanate RNA extraction solution (4 M guanidinium thiocyanate, $25 \mathrm{mM}$ sodium citrate, $0.5 \%$ sodium $\mathrm{N}$-lauroyl sarcosinate, $0.7 \% 2-\beta$-mercaptoethanol, and $\mathrm{pH}$ to 7 with $\mathrm{HCl}$ ). For IEC-6 cells, the cells were resuspended by adding the RNA extraction solution to T75 flasks.

Dot blots were done in duplicate to Hybond membranes (Amersham) using a 96-well Manifold II dot-blot apparatus (Schleicher and Schuell). Northern analysis was done on IE C- 6 cells according to standard procedures (26). Both blots were hybridized with murine plgR CDNA and were similarly washed, prehybridized, and hybridized according to standard methods, as previously described (25). To assess the consistency of loading, the blots were rehybridized with $18 \mathrm{~S}$ ribosomal oligo-deoxynucleotide (5'-CGGCATGTATTAGCTCTAGAATTACCACAG). The results for the dot blots were quantified by using Alphal mager and AlphaEase software (Alpha I nnotech) for densitometry readings.

Plasmid construction. The 5'-flanking region of the polymeric receptor gene was derived from the pl $\mathrm{gR}-\lambda-1-1$ phage clone, as described previously (24). The full-length pl gR clone was constructed by subcloning a 4.7-kb Hind III fragment of PR- $\lambda-1-1$ into a similarly digested pGL3-basic vector from Promega. All ligations were done with the Fast Link DNA ligation kit (E picentre Technologies), and the correct orientation was ascertained by restriction digestion. The nested deletion clones were created using exonuclease III and mung bean nuclease from a kit obtained from Stratagene. The del etions were done foll owing the recommended protocol. The exact sizes of the nested deletion clones were confirmed by sequencing with the dideoxy method with Sequenase 2 (US Biochemical).

A set of short-length $(-293 /+44,-246 /+44,-163 /+44$, $-110 /+44,-53 /+44)$ promoter clones were produced using sense oligonucleotides in a standard PCR reaction (25). The upstream sense ol igonucleotide was sequence specific (-293/ Bgl II : 5' -gcagatctCAGATGGTGCTCAAAA-AGTG, -246/Bgl II: 5'-gcagatctTTATGGGAACAGGGCAATC, -163/Bgl II: 5' gcaga-tctAACAATGGAGGATCTACGC, - 110/Bgl II : 5' -gcagatctAAGGAGCCAGCCAGGA-AAGC, -53/Bgl II: 5'-gcagatctTTGACTATGGGACAACGGC) and introduced an upstream Bgl II site, indicated by lowercase italics. The identical antisense primer (5'-CTTTATGTTTTTGGCGTCTTCC) was used for all reactions. The resulting PCR products were digested, gel purified, and then subcloned into the similarly cut pGL3 basic or enhancer vector that contains the heterologous enhancer SV 40.

Clones containing substitution $(\mathrm{A}<->\mathrm{C}, \mathrm{G}<->\mathrm{T})$ mutations in the murine promoter werealso devel oped by standard PCR methods. Several oligonudeotides were used including: (SM 1) 5'-AGGGCAATCCCTAGTTACTAtcccttgcctACCAAACACTAAGGAGACAT, (SM2) 5'-CTAGTTACTAGAAAGGTAAGcaacccacagAAGGAGACATTCTGTCCCAT, (SM3) 5'-GAAAGGTAAGACCAAACACT ccttctcacgTCTGTCCCATATCCTGAAAC, (SM 4) 5'-ACCAAACACTAAGGAGACATgagtgaaacgATCCTGAAACTACAACAATG, (SM5) 5'-AAGGAGACATTCTGTCCCATcgaagtc-

ccaTACAACAATGGAGGATCTAC. The italic lowercase nt indicate the site of the mutations. The same antisense primer was used as described earlier. All clones were sequenced to confirm the presence of only the desired mutation.

Two databases: Matl nspector release 2.1 (http://www.gsf.de/ cgi-bin/matsearch.pl) (30) and MacVector 5.0 subsequence 
(TFDSITES.SUBSEQ.7.0.aa) of transcriptional factor binding sequences were used to search for potential GREelements (GGTACAN NNTGTYCT) in the 5 ' -upstream region of the pl gR gene.

Nuclear extract preparation. Nuclear extracts isol ated from Caco- 2 cells transfected earlier with the GR expression vector and treated for $24 \mathrm{~h}$ with dexamethasone was used for EMSA (25). Samples were dialyzed in a buffer consisting of $20 \mathrm{mM}$ HEPES, pH 7.9, 100 mM KCl, 0.2 mM EDTA, 20\% glycerol, $0.2 \mathrm{mM}$ phenylmethylsulfonyl fluoride (PMSF), and $0.5 \mathrm{mM}$ dithiothreitol. The protein concentration of the extract was determined using the BCA protein assay reagent kit (Pierce).

EMSA. The putative steroid response region was analyzed by gel mobility shift analysis using the complementary sense (5'-GATCAAGGAGACATTCTGTCCC-AT) and antisense (5'CTAGATGGGACAGAATGTCTCCTT) primers (SM3/4). Double-stranded primers were produced by boiling and then labeled with $\left[\alpha^{-32} \mathrm{P}\right] \mathrm{dCTP}(3,000 \mathrm{Ci} / \mathrm{mmol})$ using Klenow fragment and desalted through a G25 Sephadex NAP 5 column (Pharmacia). The binding reaction consisted of $6 \mu \mathrm{g}$ of nuclear protein extract, $5 \times 10^{4}$ counts/min of the SM3/4 primer, and 100- or 1,000-fold of the competitive inhibitor (when pertinent). The master mix consisted of $5.7 \mathrm{mM} \mathrm{MgCl}$, $53.8 \mu \mathrm{M}$ 2- $\beta$-mercaptoethanol, $0.38 \mathrm{mM}$ PMSF, $10 \mathrm{mM}$ HEPES, pH 7.9, 10\% glycerol, 0.1 mM EDTA, $0.05 \mathrm{M} \mathrm{KCl}, 2.5$ $\mu \mathrm{gBSA}$, and $0.2 \mu \mathrm{g}$ of poly(dl/dC) (Pharmacia) in a 13- $\mu$ l total mixture.

The reaction also contained primers with specific mutations indicated in lower ital ized letters including: I n primers: sense 5'-GATCAAGGAGcCcggCgGTCCCAT and antisense 5'-CTAGATGGGACcGccgGgCTCCTT; Out primers: sense 5' GATCAAttcGACATTCTGgaaCAT and antisense 5'-ATGttcCAGAATGTCgaaTT; I n/Out primers: sense 5'-AAttcGcCcggCgGgaaCAT and antisense 5'-ATGttcCcGccgGgCgaaTT; N on primers: sense 5'-ccGGAtAaATTaTtTCCacg and antisense 5'-cgtGGAaAtAATtTaTCCgg; Unrelated primers: sense 5'-gAtcgGctAcctTGaCtatgct and antisense 5'-CTagcataGtCAaggTagCc; Consensus: sense 5'-GATCGCGTTGCCAGAACATGATGTTCTAATCTGAG and antisense 5'-GATCCTCAGATTAGAACATCATGTTCTGGCAACGC; \pm 2 GRE: sense 5'-GTAAGACCAAACACTAAGGAGAaATTCTtTCCCATATCCTGAA and antisense 5'-TTCAGGATATGGGAaAGAATtTCTCCTTAGTGTTTGGTCTTAC; \pm 3 GRE : sense 5'-GTAAGA C CAAACACTAAGGAGCCATTCTG gCCCATATCCTGAA and antisense 5'-TTCAGGATATGGGCCAGAATGgCTCCTTAGTGTTTGGTCTTAC; \pm 5 GRE: sense 5'-GTAAGACCAAACACTAAGGCGACATTCTGTCACATATCCTGAA and antisense 5'-TTCAGGATATGtGACAGAATGTCgCCTTAGTGTTTGGTCTTAC.

The recombinant GR protein, consisting of 44 amino acids of the DN A binding domain, was used for both gel shift (30 ng) and footprint analysis and was kindly provided by K. Yamamoto. The binding reactions were then incubated for $15 \mathrm{~min}$ at $30^{\circ} \mathrm{C}$. The gel used was a Tris-borate-EDTA gel with $5 \%$ acrylamide and $1 \%$ glycerol. The samples were then run at $250 \mathrm{~V}$ for about $2 \mathrm{~h}$, fixed, dried, and exposed to X-OMAT-AR film (E astman Kodak) overnight at $-80^{\circ} \mathrm{C}$.

DNase I footprinting. In vitro DNase I footprint analysis was performed according to the established methods (25). Briefly, the pl gR-246/+44-pGL 3-enhancer clone was digested with $\mathrm{Bgl} \mathrm{II}$ and then treated with calf intestinal phosphatase. The DNA was then kinased with $\left[\gamma-{ }^{32} \mathrm{P}\right] \mathrm{dATP}(6,000 \mathrm{Ci} / \mathrm{mmol})$ and cut with $\mathrm{Hind} \mathrm{III}$, and el ectrophoresed on a $5 \%$ polyacrylamide gel, purified, and diluted to 6,000 counts/min per $\mathrm{ml}$.

F ootprints were performed using 50 ng of recombinant GR protein as discussed earlier. Approximately 6,000 counts/min of probe were mixed with protein and the master mix as specified earlier. Serial dilutions of DNase I was added in the usual manner, and the reaction was terminated with stop solution consisting of $10 \mathrm{mM}$ EDTA, 0.2\% SDS, $400 \mathrm{mM}$ sodium acetate, and $50 \mu \mathrm{g} / \mathrm{ml}$ yeast tRNA. Samples were purified with phenol and chloroform, precipitated with ethanol, and run on a $6 \%$ polyacrylamide gel at $50 \mathrm{~W}$ for $100 \mathrm{~min}$. The location of the protected area was determined by running a Maxam-Gilbert sequencing reaction next to the footprint sample.

\section{RESULTS}

Glucocorticoids enhance polymeric receptor steadystatemR NA levels in developing rat intestineand I E C-6 cells. Quantitative dot-blot analysis was performed on duodenal samples isolated from suckling rats treated initially at day 7 of life with either corticosterone or saline for either 3 or 7 days. The bl ots were hybridized with labeled murine plgR cDNA and 18S ribosomal oligonucleotide (data not shown) that served as a standard, and the results were quantified by densitometry. Compared with vehicle-treated littermates, 3- or 7-day treatment with steroids resulted in a four- and sevenfold elevation of steady-state plgR mRNA levels, respectively (Fig $1 \mathrm{~A})$.
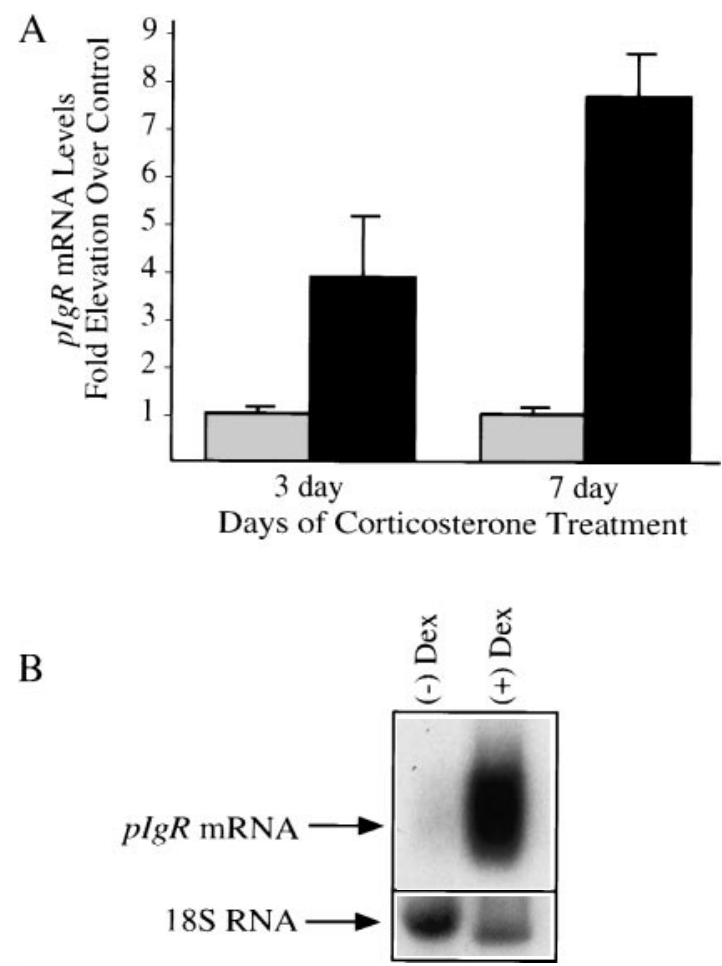

Fig. 1. Northern and dot analysis of steady-state polymeric IgA receptor (pl gR) mRNA levels from devel oping rat duodenal or IEC-6 cells treated with either corticosteroids or vehicle. A: corticosterone acetate was administered to rats beginning on day 7 of life and continued for either 3 or 7 days, at which point total RNA was isolated from duodenum. Dot blots (not shown) were hybridized first to murine pl gR cDNA probe and then 18S primer after stripping with boiling water. Densitometric analysis was performed, and variation for RNA loading was controlled for by $18 \mathrm{~S}$. All data are standardized to $\mathrm{pl} \mathrm{gR} \mathrm{mRNA} \mathrm{levels} \mathrm{from} \mathrm{vehicle-treated} \mathrm{animals.} \mathrm{Data} \mathrm{are} \mathrm{given} \mathrm{as}$ means \pm SD. B: Northern blot analysis of plgR and $18 \mathrm{~S}$ obtained from IEC-6 cells treated for $24 \mathrm{~h}$ with either dexamethasone (Dex) or vehicle. 
To evaluate whether steroids alter plgR mRNA expression in a cell line that is known to express the polymeric receptor, Northern blot analysis was performed on IEC-6 cells treated with either dexamethasone or steroid-free medium. The Northern blot was hybridized with murine plgR cDNA probe, stripped, and rehybridized to $18 \mathrm{~S}$ ribosomal deoxynucleotide. Figure 1B demonstrates a marked enhancement of steady-state pl gR mRNA transcript after $24 \mathrm{~h}$ of treatment with dexamethasone, whereas the 18S transcript confirms that a comparable amount of RNA was loaded in each lane. Taken together, these data demonstrate that glucocorticoids can substantially increase plgR mRNA steady-state levels in intestinal epithelial cells of devel oping rats and in IEC-6 cells.

$5^{\prime}$-Flanking region $(4.7 \mathrm{~kb})$ of murine $\mathrm{plgR}$ gene is responsive to glucocorticoids. The nt sequence of the 5 '-upstream region of the pl gR gene was examined for full palindromic GR-binding sites (GGTACANNNTGTYCT) using two standard transcriptional factor databases (30). Whereas several GRE half-sites (TGTYCT) were identified, neither database detected a potentially active full GRE palindrome in the entire $4.7 \mathrm{~kb} 5^{\prime}$ flanking region of the murine gene. Because no candidate hormone response sites could be identified, we tested this region experimentally using transient transfection experiments.

To study the effect of steroids on the activity of the murine pl gR promoter, the 4.7-kb pl gR-luciferase construct was used in transient transfection experiments in Caco-2 cells. Figure 2A demonstrates that in the presence of the full-length promoter $(-4740 /+44)$, there was no significant transactivation of the promoter mediated by dexamethasone. Because the Caco- 2 cell line has been reported to not synthesize a significant quantity of GR (6), we performed cotransfection experiments where GR was introduced using a mammalian expression vector. In the presence of GR vector, Caco-2 cells treated with dexamethasone had an 80-fol d higher level of pl gR promoter activity compared with cells not treated with steroids. We interpreted these data to suggest the presence of at least one glucocorticoid response el ement within the upstream 4.7-kb region of the murine $\mathrm{pl} \mathrm{gR}$ gene. Moreover, the data demonstrate the requirement of performing cotransfection experiments with GR when testing for steroid responsiveness in Caco-2 cells. All subsequent analyses were performed in the presence of GR expression vector.

Steroid responsive element was identified in immediatepromoter regi on of murinepl gR gene. To identify the approximate location of the glucocorticoid-mediated transactivation of the pl gR promoter, transient cotransfection studies were performed using a series of 12 different size 5'-flanking constructs of the plgR gene and an expression vector for GR (Fig. 2B). One day later, the cells were either treated with dexamethasone or charcoal-stripped steroid-free medium for an additional day before processing. Because the basal level of expression differs between various constructs, the data are depicted as an increase in el evation of dexamethasone-treated cells over nonsteroid-treated cells (25). From Fig. 2B, the full-length clone $(-4730 /+44)$ shows more than an 80-fold higher level of promoter activity compared with nontreated cells. Although promoter activity of the longer length clones were generally 40-fold elevated in the presence of steroids, the clones from $-1254 /+44$ to $-215 /+44$ consistently had a $20-$ fold higher level of activity compared with the empty pGL3 basic vector. More importantly, there was a dramatic reduction in promoter activity between the intermediate size $(-1254 /+44$ to $-215 /+44)$ and the smaller length $(-58 /+44)$ clones. These data were interpreted to suggest that, while we cannot rule out the presence of a more upstream element, the most potent steroid response region is located between nt -215 and -58 within the murine plgR 5'-flanking region.

To further localize the cis-acting DNA element between -215 and -58 , we created DNA fragments of various lengths and subcloned them into either pGL3 basic or enhancer vector. Promoter activity was measured following transient transfection of Caco-2 cells. Figure $2 \mathrm{C}$ demonstrates that clones containing the two largest fragments $(-293 /+44$ and $-246 /+44)$ subcl oned into the basic vector (solid bars) showed a 10-fold el evation of promoter activity in the presence of glucocorticoid. These data also show an eightfold decline in steroid-induced transactivation when going from - 246/ +44 to $-163 /+44$. The remainder of the shorter length nested clones $(-110 /+44,-53 /+44)$ exhibited comparable steroid responsiveness to that of the empty vector pGL3 basic. Subcloning the fragments into the vector pGL3 enhancer with the heterologous SV40 enhancer gave similar results (hatched bar). These data confirm the results from Fig. 2B and further limits the location of the steroid response region to nt between -215 and -163 of the murine gene.

Substitution mutation analysis of murine pl gR's ste roid response region. To further refine our analysis of the steroid response element of the plgR gene, we tested promoter transactivation of clones that contained mutations within the -215 to -163 region. Five cl ones were produced that contained a consecutive span of 10-nt mutations within this location (SM 1-SM 5). The exact nt mutated in each clone are displayed in Fig. 3 and are shown in comparison to the sequence of the comparable region in the human and rat genes. These mutant fragments (SM1-SM5) were subcloned upstream of the enhancer SV40, and promoter activity was measured. Two sets of transfections with the same mutant were either treated with medium containing dexamethasone or steroid-free 24-h posttransfection. Transient transfection experiments are displayed in Fig. 4 and demonstrate that promoter activity of clones SM3 and SM 4 was nearly $15 \%$ of the wild-type $-246 /$ +44 cl one in the presence of glucocorticoids $(P<0.001)$. The nt mutated in the SM3 and SM4 clones corresponds to bases -195 to -176 of the murine pl gR gene, which interrupts an asymmetric GRE (5'-TGAGACATTCTGTCCC- $3^{\prime}$ ) and was not detected previously using database analysis (Fig. 3). In summary, these data were interpreted to suggest that, within the immediate 4.7-kb 5'-flanking regions of the pl gR gene, the dominant glucocorticoid response element resides be- 


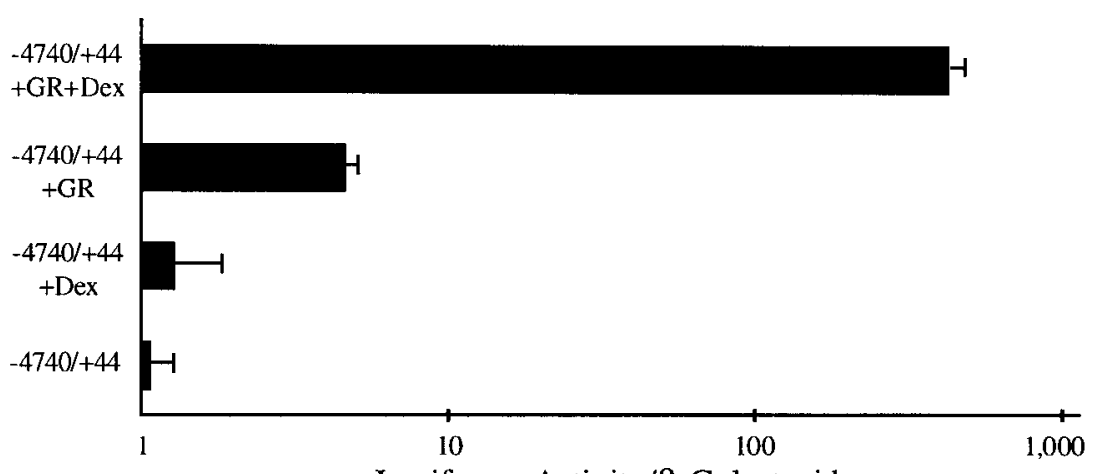

B

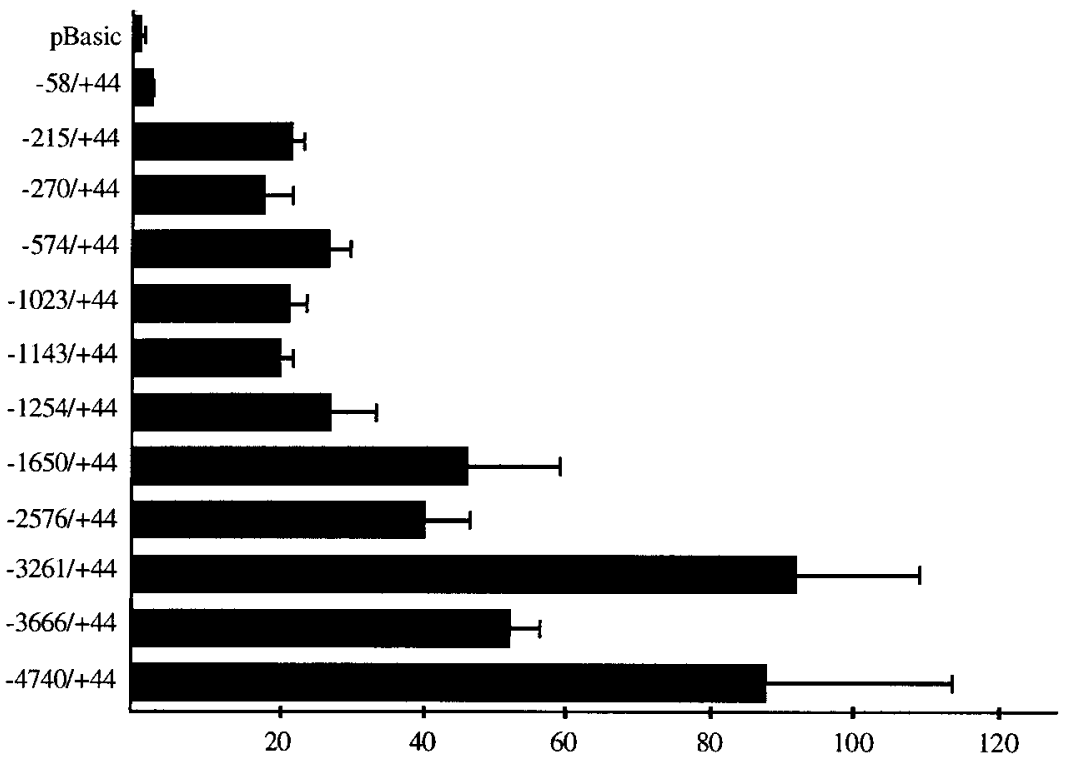

$\mathbf{C}$

Luciferase Activity/ $\beta$-Galactosidase Fold Elevation of Dex/No Dex

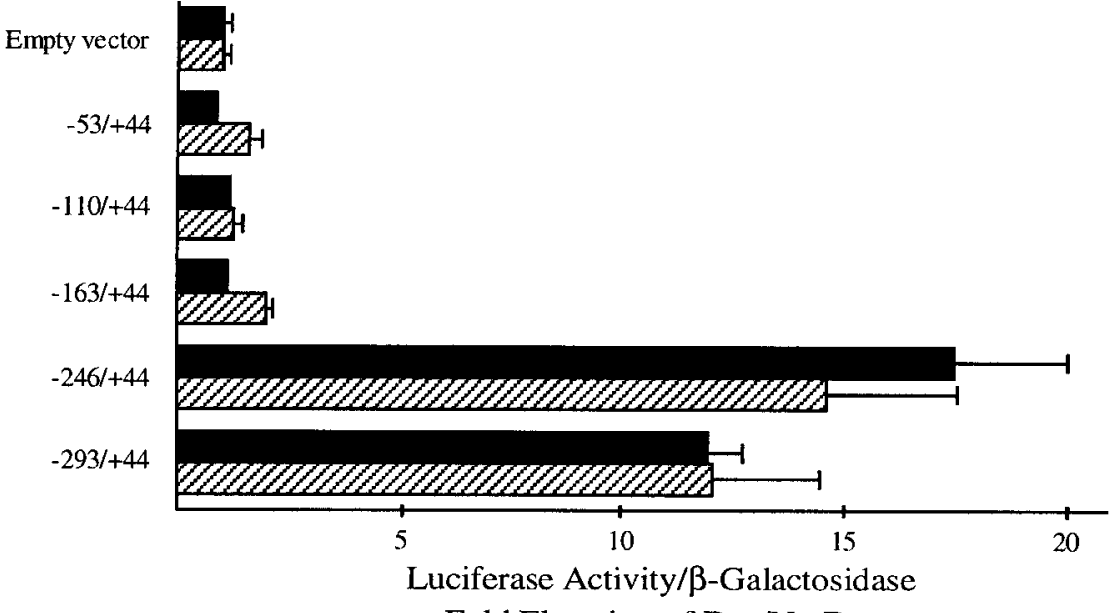

Fig. 2. plgR-nested deletion clones transiently transfected into Caco-2 either with or without glucocorticoid receptor (GR) and dexamethasone. A: luciferase reporter vector containing $4.7 \mathrm{~kb}$ of flanking regulatory region of $\mathrm{plgR}$ gene was transfected in Caco-2 cells either alone or cotransfected with vector expressing GR. Transfected cells were treated $24 \mathrm{~h}$ later either with or without dexamethasone, and promoter activity was measured 1 day later as described in MATERIALS AND METHODS. Transfection efficiency was assessed by transfecting $0.5 \mu \mathrm{g}$ of cytomegal ovirus $\beta$-galactosidase vector. Results are displayed as luciferase activity over $\beta$-galactosidase activity. B: nested deletion clones were cotransfected in presence of vector expressing GR, and cells were treated with either dexamethasone or ve hicle control medium. One day later, luciferase and $\beta$-galactosidase activity was measured. Re sults are represented as relative units of Iuciferase activity normalized to $\beta$-galactosidase activity and are displayed as multiples of increase of dexamethasone over vehicletreated cells with empty vector arbitrarily set to 1 . Data are given as means \pm SD. Each set of transfections was performed in duplicate in at least 3 separate experiments. C: PCR-derived shorter-length clones were subcloned upstream of either re porter vector pGL 3 basic (solid bars) or enhancer (hatched bars) that contains heterologous enhancer SV40. Clones were cotransfected with vector expressing GR in Caco-2 cells and treated subsequently with either dexamethasone or vehicle control. Luciferase and $\beta$-galactosidase levels were measured 1 day later, and data are given as means \pm SD. Each clone was transfected in duplicate in at least 3 separate experiments.

Fold Elevation of Dex/No Dex

tween nt -192 and -178 upstream of the murine gene's transcriptional start site.

DNase I analysis of murine plgR's flanking region with recombinant GR identifies single footprint. To confirm the results obtained from the substitution mutation studies, in vitro footprint analysis was performed of the murine pl gR promoter using recombinant GR protein. We examined the region of the promoter that spans from nt -232 to -40 in the analysis. DNase I analysis demonstrated the presence of a single foot- 
Fig. 3. DNA sequence of steroid response region in murine, human, and rat plgR. Nucleotide comparison of steroid re sponse region in murine $\mathrm{plgR}$ gene and its comparison to comparable region of human and rat gene $(10,19,26,39)$ are shown. Shaded regions correspond to location of identity between species. Locations of nt mutated in transfected clones (Fig. 4) are displayed below species comparison, whereas partial sequence of primers used in electrophoretic mobility shift assays (Fig. 6, A and B) appears above isoform comparison. Corresponding antisense oligonucleotides are not shown. Consensus GR-binding site is depicted above for comparison, with critical residues indicated by $\bullet$.

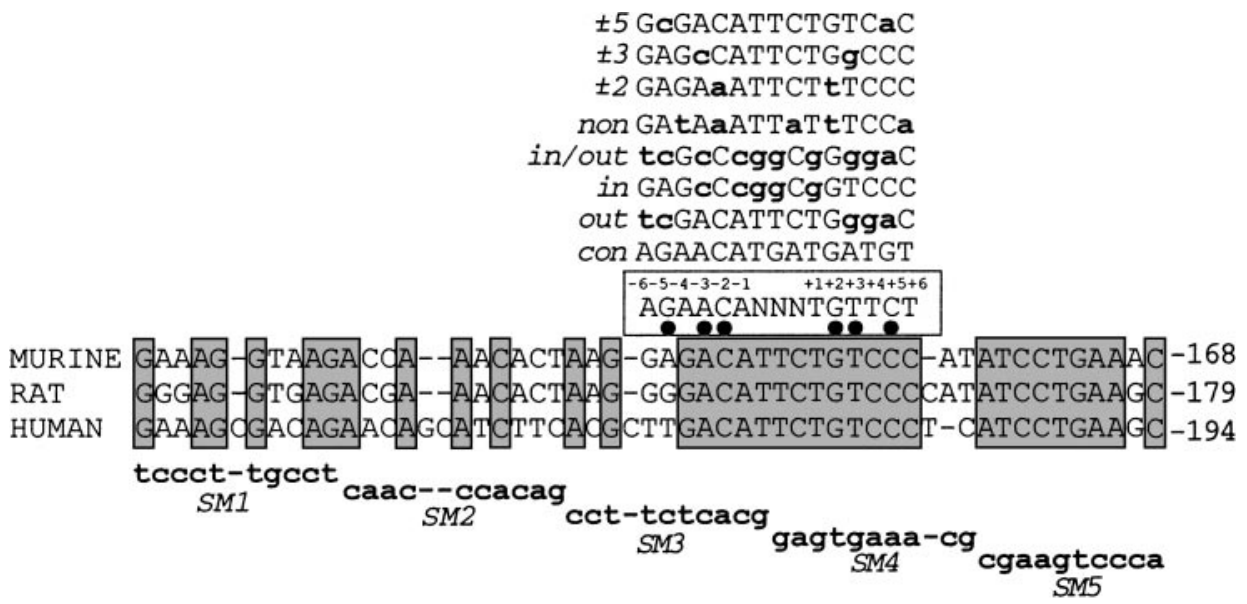

print that spans the region mutated in clones SM 3 and SM4 (nt -195 to -176) (Fig. 5). No additional footprints could be identified in the region studied. These data provides additional evidence that the nt that span between -192 and -178 represent an active glucocorticoid response element.

EMSA of GR-binding site of plgR gene To further analyze the nt within the putative steroid response element that is responsible for binding to GR, we performed standard EMSA. Double-stranded oligonucleotides that span the SM3 and SM4 (-195 to -176) region (SM3/4) were radiolabeled and used for all experiments. TheDNA sequences of each ol igonucleotide used in the EMSA are listed within MATERIALS AND METHODS, whereas the critical nt (within the GRE consensus) are displayed in Fig. 3. The addition of nuclear extracts isolated from Caco-2 cells resulted in two predominant gel shift complexes (Fig. 6A, lane 1), and one minor complex can be seen in the overexposed

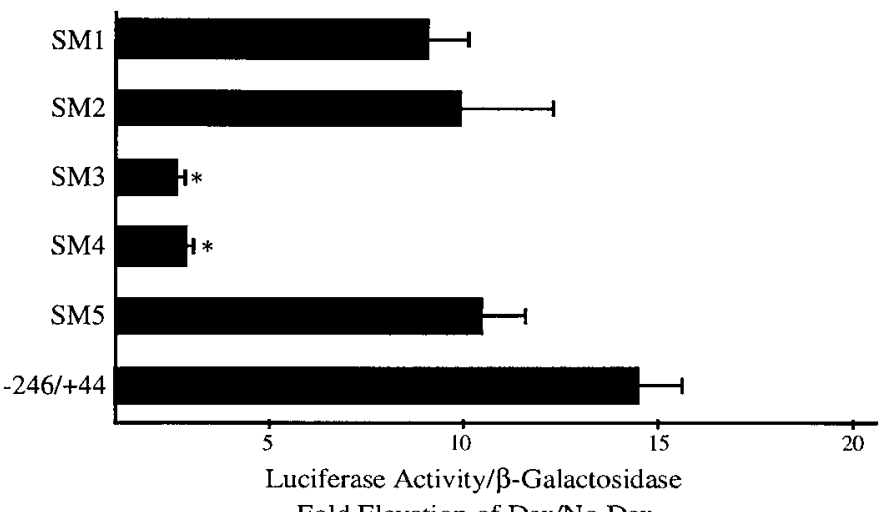

Fold Elevation of Dex/No Dex

Fig. 4. Substitution mutagenesis of steroid response region of murine $\mathrm{plgR}$ gene. Five clones each containing 10 nt mutations were transiently cotransfected into Caco- 2 cells and treated $24 \mathrm{~h}$ later with either dexamethasone or vehicle control (Fig. 3). Promoter activity was measured 1 day later and is displayed relative to wild-type $-246 /+44$ cl one that contains no mutations. Results are represented as relative units of luciferase activity normalized to $\beta$-galactosidase activity and are displayed as multiples of increases of dexamethasone over vehicle-treated cells with empty vector arbitrarily set to 1 . Data are means \pm SD. Promoter activity of SM 3 and SM4 clones was significantly less than the wild-type $-246 /+44$ clone $(*)$. Each clone was transfected in duplicate in at least 3 separate experiments.

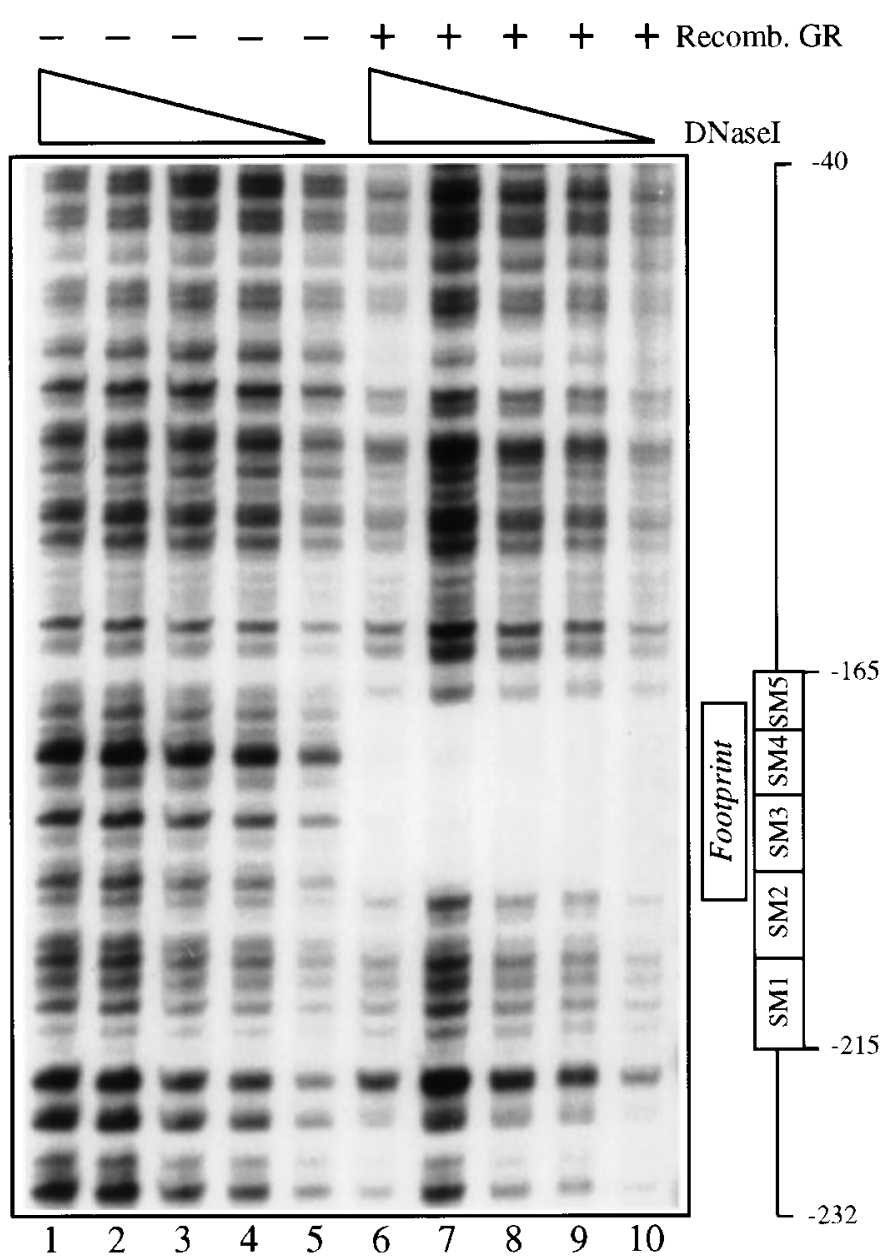

Fig. 5. DNase I footprint analysis of proximal plgR dexamethasone response element. In vitro footprint analysis of murine plgR gene region from -232 to -40 is displayed. Footprint analysis was performed in either the presence or absence of recombinant GR DNA binding domain on sense strand of DNA ( $5^{\prime}->3^{\prime}$ orientation). Varying concentrations of DNase I were used, and samples were electrophoresed as described in MATERIALS AND METHODS. Box on right indicates location of footprint relativeto DNA sequence studied by substitution mutagenesis. 
A

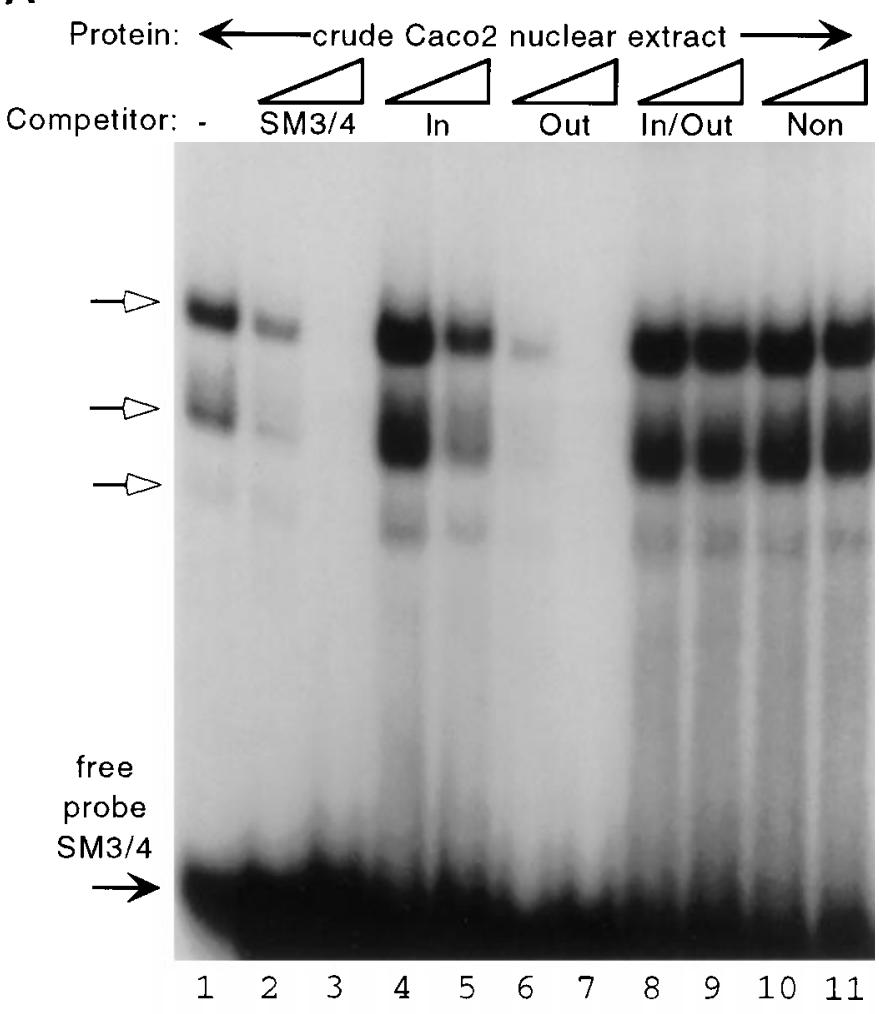

B

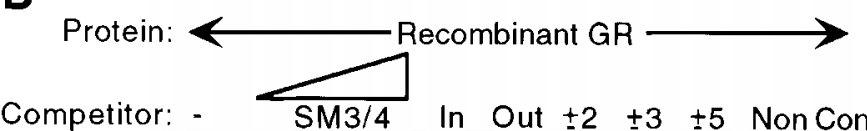

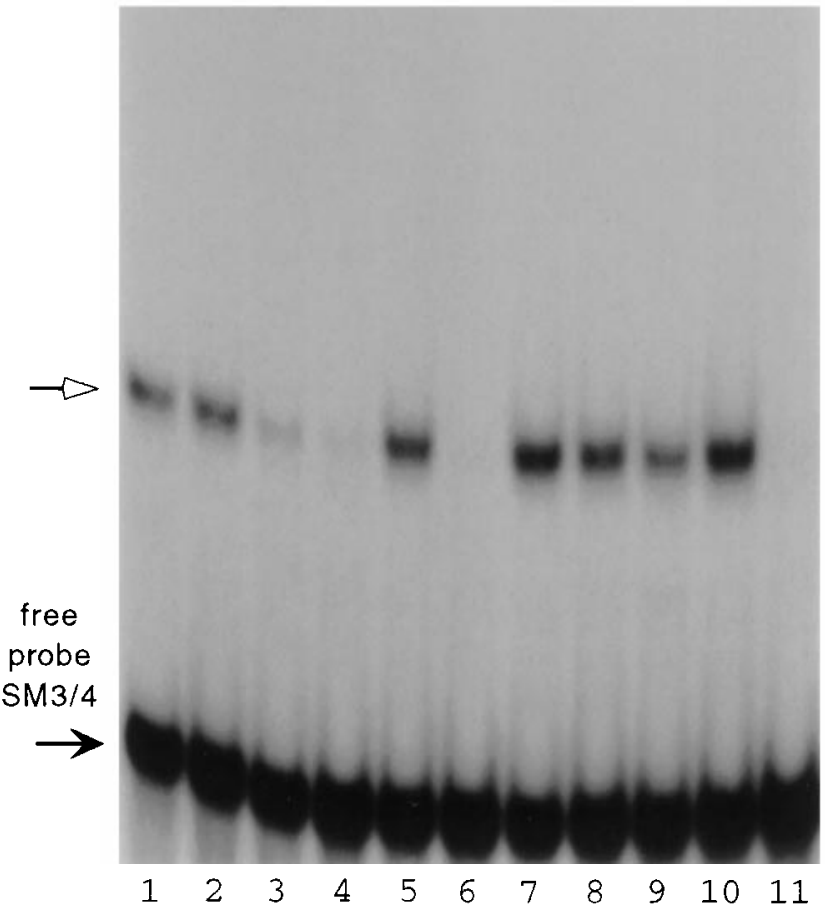

$\begin{array}{lllllllllll}1 & 2 & 3 & 4 & 5 & 6 & 7 & 8 & 9 & 10 & 11\end{array}$

autoradiogram (open arrow heads). The DNA-protein complex could be competed by the presence of 100- or 1,000-fold excess of either unlabeled SM3/4 (GRE) or the Out primers (Fig. 6A, lanes 2, 3,6,7). The Out primer contains two clusters of mutations in the outer portion of the GRE consensus that alters residue +3 , +4 and -5 (Fig. 3). The ability of the Out primer to compete for $\mathrm{GR}$ binding suggests that the remaining critical residues $(+2,-2$, and -3$)$ are sufficient to bind GR as indicated in Fig. 6A. In contrast, the band shift could not be competed with an excess of the In oligonucleotide that contains mutations that disrupts only residue -3 , indicating its critical role in binding $\mathrm{GR}$ (Fig. 6A, lanes 4 and 5). Similarly, several other primers designated Non and In/Out were also not capable of competing with the complex (Fig. 6A, lanes 8-11).

To further define the precise nt necessary for forming the DNA-GR complex, EMSA competition studies were performed with recombinant GR (Fig. 6B). The single complex could be competed with the addition of 100 or 1,000-fold excess of unlabeled cold SM3/4 primer (Fig. $6 \mathrm{~B}$, Ianes 1-4). The Out oligonucleotide was also capable of effectively competing for the complex (Fig. 6B, lane 6), as was seen earlier when crude extracts were used (Fig. 6A). A frequently used GRE consensus oligonucleotide sequence could also compete (Fig. 6B, lane 11). However, when a 1,000-fold excess of either the In or N on primers was used, neither was capable of competing for the complex (Fig. 6B, lanes 5 and 10). Interestingly, primers containing mutations to a critical symmetrical nt $( \pm 2, \pm 3$, or \pm 5$)$ all failed to compete for binding with the complex (Fig. 6B, lanes 7-9). We interpreted these data to suggest that the steroid responsive region of the $\mathrm{pl} \mathrm{gR}$ gene is located between nt -192 and -178 and that several nt within this element are critical for binding to GR.

\section{DISCUSSION}

In this study, glucocorticoids were shown to upregulate steady-state pl gR mRNA levels in both developing small intestine and in IEC-6 cells (Fig. 1). Transient transfection of a 4.7-kb murine pl gR 5'-upstream region fused to the reporter luciferase identified that the element controlling the glucocorticoid-mediated activation of promoter activity was located within this region of the gene. To identify the location of the hormone response el ement, transient transfection of fusion constructs containing various upstream regions of $\mathrm{plgR}$

Fig. 6. Electrophoretic gel shift assays of SM3/4 region including specified mutations. A: crude Caco-2 nuclear extracts and wild-type SM3/4 primer were used for all gel shift assays. Critical DNA sequence of each primer is displayed in Fig. 3 and is also discussed in MATERIALS AND METHODS. Four similarly sized ol igonucl eotides containing substitution mutations (In, Out, In/Out, Non) were used in either 100- or 1,000-fold excess (indicated by triangle) in unlabeled state in competition reactions. B: SM 3/4 probe was incubated with recombinant GR (30 ng), and increasing concentrations of unlabeled SM 3/4 (lane 2-4), or 1,000-fold excesses of In (lane 5), Out (lane6), \pm 2 (lane 7), \pm 3 (lane 8), \pm 5 (lane 9), Non (lane 10), and Con (Consensus; lane 11) were used in competitive reactions. 
fused to luciferase was performed. Analysis of a series of clones identified that $\mathrm{nt}$ between -215 and -163 contained the putative glucocorticoid response el ement (Fig. 2). Scanning mutagenesis of this region identified that the element resides between nt -192 and -178 from the transcriptional start site (Fig. 4). This 20-nt span identified by a combination of nested deletion and scanning mutagenesis analysis contained an asymmetric GRE that was not previously identified by searching with transcription factor databases (Fig. 3). The ability of the murine element to bind to GR was further characterized using DNase I footprint and EMSA (Figs. 5 and 6). Although we could not definitively rule out a weak response el ement in the more upstream portion of the cloned fragment, these data suggest that the most potent steroid response element in the portion of the plgR gene that was studied is located in the genes in the immediate upstream region. I nter estingly, a second asymmetric GRE is located between nt -1338 and -1352 (5'-AATACTGCCTGTCCT-3'), and its deletion from the shorter-length clones ( $<1,254 \mathrm{bp}$ ) may account for the modest $50 \%$ reduction of promoter activity seen in the shorter-length clones (Fig. 2).

The upstream region of the murine $\mathrm{pl} g \mathrm{R}$ gene contains several half GRE sites, which generally are insufficient by themselves to confer hormoneresponsiveness. In contrast, two half-GRE (AGAACA) separated by a three-base pair spacer are each able to bind a GR monomer and activate promoter activity (2). When the murine sequence is compared with that of the comparable steroid response region in rats and humans, nt differences are limited to bases at position -5 and -6 (Fig. 3) (19, 25). In general, the critical nt in the GRE are the four major guanine/cytosine $\mathrm{nt}$ at positions \pm 2 and \pm 5 (35). Although the $n t$ at position -5 is necessary for establishing hydrogen bond interactions with the lysine 442 residue of GR, substitution mutation analysis reveals that guanine, adenine, or thymine bases are equally active, whereas cytosine would dramatically reduce its steroid responsiveness (44). Therefore, we would predict that the divergent nt seen at position -5 should not dramatically alter GR binding. In contrast, the thymine at position -6 in the human response element is different from the adenine and guanidine seen in the rat and murine el ement, respectively. Adenine and guanine bases at this position are equally active, whereas thymine would severely impair the induction of the gene by steroids $(38,44)$. Interestingly, a thymine nt at position -6 should still be capable of maintaining a marginal ability to bind to the progesterone receptor (23).

Because glucocorticoid response elements are capable of binding to the androgen receptor, the identified element may account for the androgen responsiveness of pl gR in both prostate and in epithelial cells of the lacrimal gland (11, 37). Dexamethasone responsiveness of $\mathrm{plgR}$ is also tissue specific, since production is el evated in hepatocytes and salivary cells in a dose- and time-dependent manner, while decreasing in the mammary gland and cerviovaginal secretions (5, 40, 41). Contrary to our findings, corticosteroids were previ- ously shown to decrease the total cellular concentration of the secretory component in 10-day-ol d rat intestine (4).

Estrogen that binds to a slightly different hormone response element (AGGTCANNNTGACCT) has also been shown to alter the steady-state levels of plgR mRNA in a complex pattern (35). More specifically, estrogen represses pl gR expression in the mammary gland but enhances its synthesis in the epithelial cells of the uterus $(18,31-33,42)$. The upstream region of the murine $\mathrm{plgR}$ gene contains several estrogen halfsites and a complete palindrome (5'-AGTTCTGCCTGACCT-3') located between $n t-736$ and $-722(19,25)$. This particular el ement may account for the responsiveness of the gene to estrogen, but it has not yet been tested experimentally.

The steroid induction of plgR expression may have several significant physiological consequences. Recent in vitro evidence suggests that the receptor is also capable of carrying antibody-antigen complexes from the basolateral to the apical membrane (17). This represents a unique mechanism used to expel antigenantibody complexes from the basolateral compartment. By upregulating plgR expression, corticosteroids may in turn expedite receptor-antibody-antigen interactions and enhance the removal of antigen-antibody complexes. Glucocorticoids also suppress the synthesis of several cytokines, including tumor necrosis factor- $\alpha$, interferon- $\gamma$, and interleukin-4, which have all been shown to upregulate $\mathrm{pl} g \mathrm{R}$ expression $(1,29)$. Therefore, the ultimate role that steroid administration has on plgR synthesis in an inflamed organ like the adult intestine may be complex and has not been established.

Recent evidence suggests that steroid receptors alter the transcription of primary genes by interacting with several coactivators, including steroid receptor coactivator (SRC-1) and CBP/p300 (CAMP response elementbinding protein). Coactivators that interact with GR have been proposed to stabilize the preinitiation complex by binding to basal transcriptional factors such as TBP, TFIID, and TFIIB which induces transactivation (27). Interestingly, several of these coactivators also haveintrinsic histoneacetyl-transferaseactivities which have been shown to induce chromatin remodeling via histone acetylation, resulting in the removal of transcriptional repressing nucleosomes (25). Ther efore, coactivators may enhance steroid-induced transactivation by two mechanisms: 1) histone acetylation and remodeling and 2) stabilization of the preinitiation complex (15). Steroid-induced histone remodeling is also a general mechanism that may make promoters accessible to critical transcriptional factors. Because endogenous steroid levels in the rodent rise at the time of weaning, hormone-induced remodeling of chromatin is a plausible mechanism that may alter the expression pattern of several of these genes at weaning.

Glucocorticoids have been shown to play a critical role in the devel opment of several organs, including the lung where among other roles it is known to induce surfactant protein D synthesis (34). The role of exogenous glucocorticoids in the precocious maturation of the intestine is also very well documented (14). Gluco- 
corticoids have been proposed as a regulator of an intrinsic clock that controls in the expression pattern of several developmentally expressed genes in the intestine. Despite recent progress in the isolation and characterization of several such genes, including lactase and sucrase-isomaltase, investigators have yet to describe the presence of a classic glucocorticoid cisacting element or an indirect trans-element that controls their expression $(3,43)$.

Although this study demonstrates that $\mathrm{plgR}$ is a primary steroid response gene that binds GR directly, other intestinal genes may be secondary response genes that require protein synthesis (8). Sucraseisomaltase may represent a secondary response gene because its induction by steroids is delayed (22). Steroids are capable of inducing the synthesis of several transcription factors, including $\mathrm{C} / \mathrm{EBP}-\alpha, \mathrm{C} / \mathrm{EBP}-\beta$, $C / E B P-\gamma$, and $I \kappa B$, which in turn may influence the downstream expression of a group of secondary response genes $(7,12)$. Although both $C / E B P-\beta$ and C/EBP- $\gamma$ mRNA transcripts have been detected in the intestine, only C/EBP- $\alpha$ has been identified immunohistochemically in terminally differentiated cells of the villus (28). Such a transcription factor represents a potential mediator of steroid-induced regulation of genes expressed in the intestine. In fact, such a secondary response is most consistent with the transcriptional cascade model that is appealing yet not proven in intestinal development.

We give special thanks to S. Smale (University of California, LoS Angeles, UCLA) for hel pful discussions.

This study was supported by the National Institute of Child Health and Human Development Grant HD-34706; Crohn's Colitis Foundation of America Grant 016714; Fellowships from the Robert Wood J ohnson Foundation F aculty Training Grant and theAmerican Gastroenterology I ndustry Training Award 942455; and the National Science Foundation, California Alliance for Minority Participation (E. M. Gutierrez).

Address for reprint requests and other correspondence: M. G Martín, UCLA School of Medicine, 10833 Le Conte Ave, Dept. of Pediatrics, Div. of Gastroenterology 12-383 MDCC, Los Angeles, CA 90095-1752 (E-mail: mmartin@mednet.ucla.edu).

Received 12 May 1998; accepted in final form 1 March 1999.

\section{REFERENCES}

1. Almawi, W. Y., H. N. Beyhum, A. A. Rahme, and M. J . Rieder. Regulation of cytokine and cytokine receptor expression by glucocorticoids. J . Leukoc. Biol. 60: 563-572, 1996.

2. Beato, M., S. Chávez, and M. Truss. Transcriptional regulation by steroid hormones. Steroids 61: 240-251, 1996.

3. Boukamel, $\mathbf{R}_{\text {., }}$ and J .-N. Freund. The cis-element CE-LPH 1 of the rat intestinal lactase gene promoter interacts in vitro with several nuclear factors present in endodermal tissues. FEBS Lett. 353: 108- 112, 1994.

4. Buts, J .-P., and D. L. Delacroix. Ontogenic changes in secre tory component expression by villous and crypt cells of rat small intestine. I mmunology 54: 181-187, 1985.

5. Buts, J . P., J . P. Vaerman, and G. Lescoat. Ontogeny of the receptor for polymeric immunoglobulins in rat hepatocytes. Gastroenterol ogy 102: 949-955, 1992

6. Cortese, J . F., J . L. Majewski, D. W. Crabb, H. J . E denberg, and $\mathbf{V}$. W. Yang. Characterization of the $5^{\prime}$-flanking sequence of rat class I alcohol dehydrogenase gene. J. Biol. Chem. 269: 21898-21906, 1994

7. Cram, E. J ., R. A. Ramos, E. C. Wang, H. H. Cha, Y. Nishio, G. L. Firestone. Role of the CCAAT/enhancer binding protein- $\alpha$ transcription factor in the glucocorticoid stimulation of p21 waf1/ cipl gene promoter activity in growth-arrested rat hepatoma cells. J . Biol. Chem. 273: 2008-2014, 1998.

8. Dean, D. M., and M. M. Sanders. Ten years after: reclassification of steroid-responsive genes. Mol. Endocrinol. 10: 14891495, 1996.

9. Diamond, J. M. Hard-wired local triggering of intestinal enzyme expression. Nature 324: 408, 1986.

10. Fodor, E., A. Feren, and A. J ones. Isolation and genomic analysis of the rat polymeric immunoglobulin receptor gene terminal domain and transcriptional control region. DNA Cell Biol. 16: 215-225, 1997.

11. Gao, J ., R. W. Lambert, L. A. Wickham, G. Banting, and D. A Sullivan. Androgen control of secretory component mRNA levels in the rat lacrimal gland. J. Steroid Biochem. Mol. Biol. 52: 239-249, 1995.

12. Gotoh, T., S. Chowdhury, M. Takiguchi, and M. Mori. The glucocorticoi-responsive gene cascade. J . Biol. Chem. 272: 36943698, 1997.

13. Henning, S. J . Postnatal devel opment. Coordination of feeding digestion and metabolism. Am. J. Physiol. 241 (Gastrointest. Liver Physiol . 4): G199-G214, 1981.

14. Henning, S. J ., D. C. Rubin, and R. J . Shulman. Ontogeny of the intestinal mucosa. In: Physiology of the Gastrointestinal Tract, edited by L. R. J ohnson. New York: Raven, 1994, p. 571-610.

15. J enster, G., T. E. Spencer, M. M. Burcin, S. Y. Tsai, M. J . Tsai, and B. W. O'Malley. Steroid receptor induction of gene transcription: a two-step model. Proc. Natl. Acad. Sci. USA 94: 7879-7884, 1997.

16. Kaetzel, C. S., V. J . Blanch, P. M. Hempen, K. M. Phillips, J . F. Piskurich, and K. R. Youngman. The polymeric immunoglobulin receptor: structure and synthesis. Biochem. Soc. Trans. 25: 475-480, 1997

17. Kaetzel, C. S., J . K. Robinson, K. R. Chintalacharuvu, J . P. Vaerman, and M. E. Lamm. The polymeric immunoglobulin receptor (secretory component) mediates transport of immune complexes across epithelial cells: a local defense function for I gA. Proc. Natl. Acad. Sci. USA 88: 8796-8800, 1991.

18. Kaushic, C., J . M. Richardson, and C. R. Wira. Regulation of polymeric immunogl obulin A receptor messenger ribonucleic acid expression in rodent uteri: effect of sex hormones. Endocrinology 136: 2836-2844, 1995.

19. Kushiro, A., and T. Sato. Polymeric immunoglobulin receptor gene of mouse, sequence, structure and chromosomal location. Gene204: 277-282, 1997

20. Lamm, M. E. Interaction of antigens and antibodies at mucosal surfaces. Annu. Rev. Microbiol. 51: 311-340, 1997.

21. Lamm, M. E., J. G. Nedrud, C. S. Kaetzel, and M. B Mazanec. IgA and mucosal defence: review article. APMIS 103: 241-246, 1995.

22. Leeper, L. L., and S. J . Henning. Development and tissue distribution of sucrase-isomaltase mRNA in rats. Am. J . Physiol 258 (Gastrointest. Liver Physiol . 21): G52-G58, 1990.

23. Lieberman, B. A., B. J . Bona, D. P. Edwards, and S. K. Nordeen. The constitution of a progesterone response element. Mol. Endocrinol. 7: 515-527, 1993.

24. Martín, M. G., E. M. Gutierrez, J . T. Lam, T. W. H. Li, and J . Wang. Genomic cloning and structural analysis of the murine polymeric receptor ( $\mathrm{pl} \mathrm{gR}$ ) gene and promoter region. Gene 201 189-197, 1997.

25. Martín, M. G., J. Wang, T. W. H. Li, J. T. Lam, E. M. Gutierrez, R. S. Solorzano, and H. V. Tsai. Characterization of the $5^{\prime}$-flanking region of the gene for the murine polymeric receptor (pl gR). Am. J. Physiol. 275 (Gastrointest. Liver Physiol. 38): G778-G788, 1998.

26. Martín, M. G., S. V. Wu, and J . H. Walsh. Hormonal control of intestinal Fc receptor gene expression and immunoglobulin transport in suckling rats. J . Clin. I nvest. 91: 2844- 2849, 1993.

27. McE wan, I. J ., A. P. H. Wright, and J . Gustafsson. Mechanism of gene expression by the glucocorticoid receptor: role of protein-protein interactions. Bioessays 19: 153-160, 1996.

28. Oesterreicher, T. J ., L. L. Leeper, M. J . Finegold, G. J . Darlington, and S.J . Henning. Intestinal maturation in mice lacking CCAAT/enhancer-binding protein a (C/EPB $\alpha)$. Biochem. J . 330: 1165-1171, 1998 
29. Piskurich, J. F., K. R. Youngman, K. M. Phillips, P. M. Hempen, M. H. Blanchard, J . A. France, and C. S. Kaetzel. Transcriptional regulation of the human polymericimmunoglobulin receptor gene by interferon- $\gamma$. Mol. I mmunol . 34: 75-91, 1997.

30. Quandt, K., K. Frech, H. Karas, E. Wingender, and T. Werner. Matl nd and Matl nspector-new fast and versatile tools for detection of consensus matches in nucleotide sequence data. Nucleic Acids Res. 23: 4878-4884, 1995.

31. Richardson, J ., C. Kaushic, and C. R. Wira. Estradiol regulation of secretory component: expression by rat uterine epithelial cells. J . Steroid Biochem. Mol. Biol . 47: 143-149, 1993.

32. Richardson, J. M., C. Kaushic, and C. R. Wira. Polymeric immunoglobulin $(\mathrm{Ig})$ receptor production and IgA transcytosis in polarized primary cultures of mature rat uterine epithelial cells. Biol. Reprod. 53: 488-498, 1995.

33. Rosato, R., H.J ammes, L. Belair, C. Puissant, J .-P. Kraehenbuhl, and J . Djiane. Polymeric-Ig receptor gene expression in rabbit mammary gland during pregnancy and lactation: evolution and hormonal regulation. Mol. Cell. Endocrinol. 110: 81-87, 1995.

34. Rust, K., L. Bingle, W. Mariencheck, A. Persson, and E. C. Crouch. Characterization of the human surfactant protein $D$ promoter: transcriptional regulation of SP-D gene expression by glucocorticoids. Am. J . Respir. Cell Mol. Biol. 14: 121-130, 1996.

35. Slater, E. P., H. Hesse, and M. Beato. Regulation of transcription by steroid hormones. Ann. NY Acad. Sci. 733: 103-112, 1994.

36. Spencer, T. E., G. J enter, M. Burcin, C. D. Allis, J . Zhou, C. Mizzen, N. Mckenna, S. A. Onate, S. Tsai, M. Tsai, and B. O'Malley. Steroid receptor coactivator-1 is a histone acetyltransferase. Nature 389: 194-197, 1997.
37. Stern, J . E., S. Gardner, D. Quirk, and C. R. Wira. Secretory immune system of the male reproductive tract: effects of dihydrotestosterone and estradiol on IgA and secretory component levels. J . Reprod. I mmunol. 22: 73-85, 1992.

38. Verrijdt, G., F. Claessens, J . Swinnen, B. Peeters, G. Verhoeven, and $\mathbf{W}$. Rombauts Characterization of the human secretory component gene promoter. Biochem. Soc. Trans. 25, Suppl.: 186S, 1997.

39. Verrijdt, G., J . Swinnen, B. Peeters, G. Verhoeven, W. Rombauts, and F. Claessens. Characterization of the human secretory component gene promoter. Biochim. Biophys. Acta 1350: 147-154, 1997.

40. Wira, C. R., and E. M. Colby. Regulation of secretory component by glucocorticoids in primary cultures of rat hepatocytes. J . Immunol. 134: 1744-1748, 1985.

41. Wira, C. R., and R. M. Rossoll. Glucocorticoid regulation of the humoral immune system. Dexamethasone stimulation of secretory component in serum, saliva, and bile. Endocrinology 128: 835-842, 1991.

42. Wira, C. R., J . E. Stern, and E. Colby. Estradiol regulation of secretory component in the uterus of the rat: evidence for involvement of RNA synthesis. J . Immunol. 133: 2624-2628, 1984.

43. Wu, G. D., W. Wang, and P. G. Traber. I solation and characterization of the human sucrase-isomaltase geneand demonstration of intestine-specific transcriptional elements. J . Biol. Chem. 267: 7863-7870, 1992.

44. Zilliacus, J ., A. P. H. Wright, J . Carlstedt-Duke, and J . A. Gustafsson. Structural determinants of DNA-binding specificity by steroid receptors. Mol. Endocrinol. 9: 389-400, 1995.

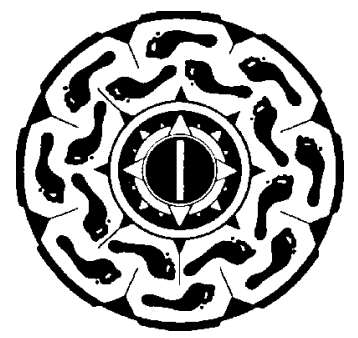

